\title{
Julius Caesar's Late Onset Epilepsy: A Case of Historic Proportions
}

\author{
Richard S. McLachlan
}

\begin{abstract}
This is a case report of Julius Caesar's epilepsy that onset when he was 54-years-old. The differential diagnosis of late onset epilepsy is discussed and the rationale presented for concluding from the clinical presentation that the cause was neurocysticercosis. That this man's disease and its consequences altered the course of history is a very real possibility.
\end{abstract}

RÉSUMÉ: L'épilepsie à début tardif de Jules César : un cas qui a eu des conséquences historiques. Il s'agit d'une analyse de l'histoire d'épilepsie rapportée chez Jules César, dont la maladie aurait débuté alors qu'il avait 54 ans. Nous discutons du diagnostic différentiel de l'épilepsie à début tardif et des raisons qui motivent notre conclusion. À notre avis, il s'agissait d'une neurocysticercose à cause des manifestations cliniques qu'il a présentées. Il est fort possible que la maladie de cet homme et ses conséquences aient modifié le cours de l'histoire.

Can. J. Neurol. Sci. 2010; 37: 557-561

The prevalence of epilepsy at any one point in time in the general population is $0.7 \%$ or one in about 150 people. However, the lifetime prevalence or the risk of developing epilepsy at some point in life is $3 \%{ }^{1}$ The incidence is higher in childhood and the elderly and lowest during middle age. Although the prevalence of epilepsy appears to be remarkably consistent from place to place and presumably has changed little over time, the causes and thus the differential diagnosis of new onset seizures depend on many factors including the age at presentation. This is illustrated by the following case report of a man who developed seizures for the first time in his fifties. Although the patient (Figure 1) is generally not identified in reports of this nature, an exception can be made in this case. His name is Gaius Julius Caesar (100-44BC).

The most definitive information about the life and health of Caesar comes from two biographers writing about 100-150 years after his death, the Greek Plutarch (75AD): "he was distempered in the head and subject to an epilepsy" "2 and the Roman Suetonius (119AD): "It is said that he was tall, of a fair complexion, round limbed, rather full faced, with eyes black and piercing; and that he enjoyed excellent health, except towards the close of his life, when he was subject to sudden fainting-fits, and disturbance in his sleep. He was twice seized with the falling sickness while engaged in active service". ${ }^{3}$ Shakespeare relied heavily on their writings while formulating the structure and dialogue, ("He hath the falling sickness") for his famous tragedy Julius Caesar. So what might have caused this formidable soldier and great leader to develop epilepsy late in his life?

\section{CASE}

When Caesar crossed the Rubicon in 50BC little did he know that his famous quote, "the die is cast", would not only be confirmed by his subsequent civil war with Pompey but by consequences emanating from this decision that would ultimately impact on his health.

During the Roman civil war, Caesar led his troops against Pompey's forces at several battlefields distributed from Spain to Greece. After his decisive victory over Pompey at the Battle of Pharsalus in Greece, he pursued him to Egypt. Pompey was killed but Caesar stayed on supporting Cleopatra in more ways than one in her civil war with her brother Ptolemy. This liaison resulted in a child, Caesarion. After winning major battles in both Egypt and the Middle East, he returned to Rome in 47BC. It was around this time that another famous quote was attributed to him after a major battle in modern day Turkey, "Veni, vidi, vici!" (I came, I saw, I conquered). Within the following year, at the age of 54 years, the conqueror was stricken by a witnessed seizure while preparing to fight the remnants of Pompey's troops at the Battle of Thapsus in modern day Tunisia. "He perceived the approaches of it before it had too far disordered his senses; and as soon as he began to shake, took care to be removed to a neighboring fort". ${ }^{2}$ This appeared to be a brief convulsion preceded by an aura and possible focal motor activity. ${ }^{4}$ Caesar then traveled to Cordoba in Spain where he defeated Pompey's sons at the Battle of Munda and is said to have had another seizure. This last battle ended the civil war and he thus returned to Rome. 


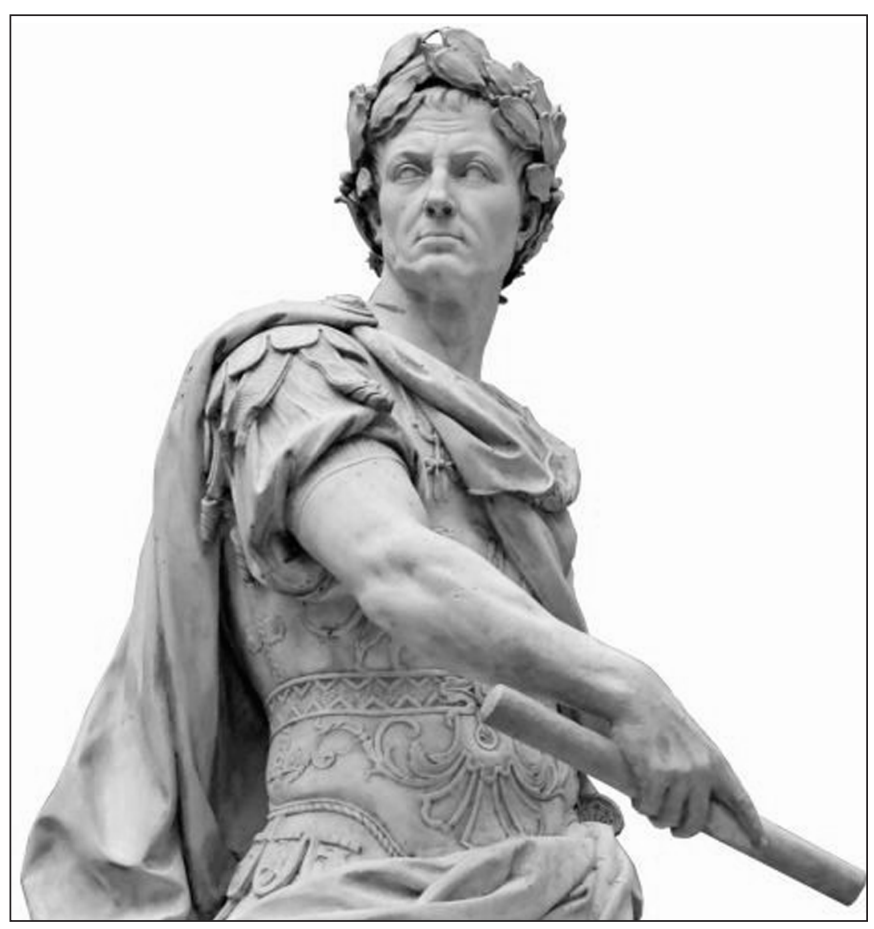

Figure 1: Caesar in his prime.

During his final two years in Rome there were at least two other documented spells suggestive of partial or focal seizures. ${ }^{2,3}$ Both occurred while attending to his duties in the Senate. During one, he felt dizzy and appeared confused for about a minute but with no loss of consciousness or alteration in ability to speak normally. In the other, there was brief body trembling for a few seconds that caused him to drop some papers that he was holding. Consciousness may have been impaired in the latter as he did not appear to realize what had happened. He was able to carry on normally immediately after both of these.

He was otherwise healthy ${ }^{2,3}$ except for occasional severe headaches over many years that were possibly related to migraine from their description. ${ }^{4}$ Birth and development were normal. There was no past history of febrile seizures or other spells. Despite his extensive military experience, he had no previous known head injuries. As a general in the Roman army and head of government his work was associated with the expected degree of stress, a major trigger but not a cause of seizures. It is not surprising that his two documented major seizures occurred around the time he was preparing his troops for battle. He was temperate in the use of wine. He was known to have had several liaisons with women other than his wife. There was a family history of "the falling sickness" (seizures) in his son, Caesarion, during childhood and in two distant relatives, Caligula and Britannicus, also starting in childhood. His only other child, a daughter Julia was fine.

There is no reason to suspect that his examination would have revealed anything other than a bright, articulate and physically fit man in whom cognition, the neurological exam and general physical exam were normal.
Table: Causes of late onset epilepsy

\section{Focal Epilepsy}

Tumor

Head Trauma

Vascular (mainly stroke)

Dementia

Chronic Infection

\section{Generalized Epilepsy}

Idiopathic (genetic)

During the two years after his seizures began and before his untimely death at the hands of assassins, no new neurological symptoms developed and he remained otherwise healthy. Towards the end of his life he refused to heed warnings of an impending assassination plot suggesting to some historians the possibility of suicidal tendencies related to depression, a condition with known increased prevalence in epilepsy.

\section{DISCUSSION}

Most interpretations of Caesar's medical condition agree that he had epilepsy rather than some other paroxysmal disorder such as Meniere's disease. ${ }^{5}$ The differential diagnosis in any patient with newly diagnosed epilepsy (Table) is best approached by first determining whether the seizures are focal or generalized in origin. An accurate history from the patient and those who have observed the seizures will often provide sufficient information to make this determination. In this case, the presence of a warning, the suggestion of a localized motor onset and the occurrence of

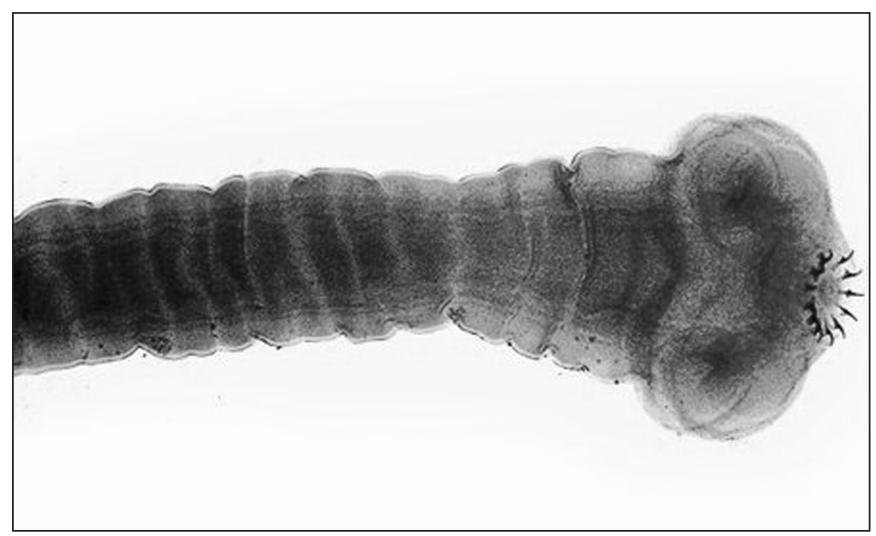

Figure 2: Scolex or "head" of the tapeworm that is attached to the intestinal wall by a circle of hooks. (Public domain courtesy of CDC, Atlanta) 


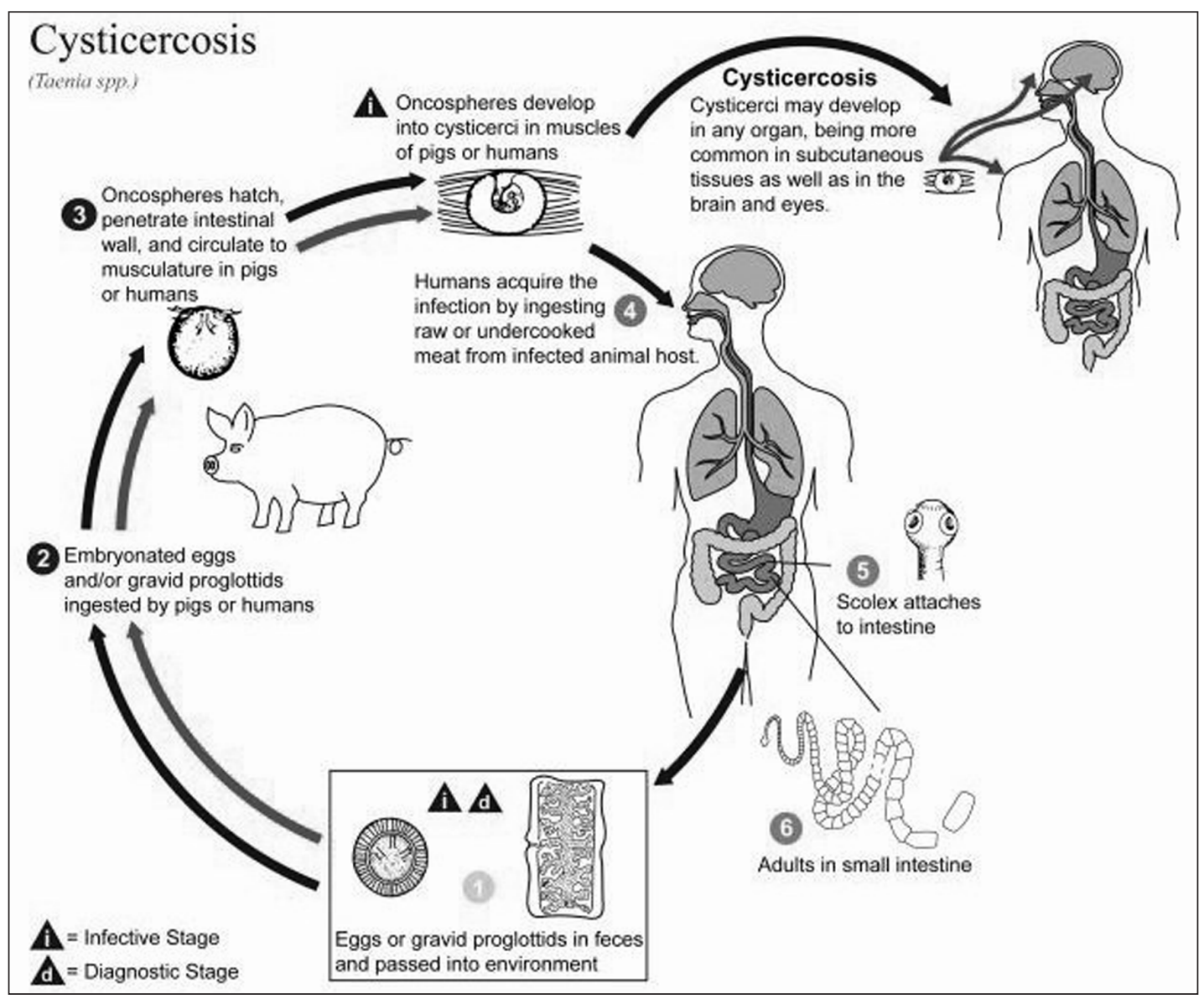

Figure 3: Lifecycle of the pork tapeworm. (Public domain courtesy of CDC, Atlanta)

smaller spells lend support to the possibility of focal seizures with secondary generalization possibly from the frontal or temporal lobe. Although most seizures from these areas are simple or complex partial, progression to a generalized tonicclonic seizure is not uncommon particularly if antiepileptic drug treatment has not yet been started. Primary generalized or idiopathic (genetic) epilepsy cannot be ruled out in this case considering the family history of seizures $^{6}$ but against this diagnosis are the suggestive features of focal onset noted above; further, generalized epilepsy is a condition generally starting in childhood as was the case in Caesar's three relatives known to have seizures. Presentation in the sixth decade would be unusual. Nonetheless Caesar may well have carried what we now would call a "genetic trait" for the development of epilepsy given the appropriate environmental circumstances.

One could hypothesize that the development of focal epilepsy in Julius Caesar relates to complications at his birth that folklore has it was by caesarian section. However there are a couple of problems with this theory. C-section and the conditions that might lead to it (eg; prolonged or delayed labor) are associated with an increased risk of epilepsy but only in the first year of life. ${ }^{7}$ Furthermore, in ancient times, no woman survived this form of delivery and Caesar's mother lived for many years after he was born. Thus Caesar's birth would not have been by caesarean section. The name of this procedure is not an eponym but more likely derives from the Latin word caedere "to cut".

An important consideration in any middle-age person who presents with seizures is the possibility of brain tumor either malignant or benign that can now be detected easily with modern imaging using CT or preferably MRI. Gomez et al suggested that Caesar had a benign tumor such as a meningioma or low grade glioma. ${ }^{8}$ However for such untreated lesions to present with infrequent seizures and remain otherwise asymptomatic for two years would be unusual. ${ }^{9}$ Certainly a benign tumor cannot be ruled out as a cause but from an epidemiological perspective, the condition described below would be favoured in the differential diagnosis. Stroke and head trauma are other possible causes of focal epilepsy at this age but there is no evidence of either in the historical records of Caesar's life. Although people in their fifties were considered to be old in ancient times, dementia is unlikely to present with seizures at this age.

Chronic infection can present with seizures. Caesar is said to have had a prodigious sexual appetite that involved mainly women but possibly also men. According to Suetonius, a speech by one of his contemporaries boldly described him as "every woman's man, and every man's woman." ${ }^{3}$ If true, and not just 
unflattering hyperbole by his enemies, then Caesar would have been at high risk for sexually transmitted disease. Hughlings Jackson, the great classical neurologist and one of the first epileptologists argued that Caesar's "falling sickness" onsetting late in life was most likely caused by neurosyphilis. ${ }^{10}$ The occurrence of seizures as a result of syphilitic infection is common but not without other signs of the illness. ${ }^{11}$ Similarly malaria, tuberculosis and other chronic granulomatous infections which Caesar may have been exposed to in his travels, can cause seizures but in association with other signs of encephalopathy. Caesar continued to function normally at a very high level as a Roman senator showing no other new neurological symptoms or signs during the two years he lived after the first documented seizure. Apart from the "falling sickness" he remained in good physical health until his assassination in 44BC. It has been suggested that he may have become depressed because he could not achieve his ambition to be "king" of Rome. However his epilepsy may well have contributed to this considering the recognized comorbidity between the two conditions. ${ }^{12}$

So why did Caesar begin having seizures late in life? There is one infection that typically could remain undetected and asymptomatic other than seizures for two years. Neurocysticercosis is the most common cause of focally originating seizures in parts of the world where the pig tape worm is endemic. ${ }^{13}$ Cysticercosis was known in southern Europe in ancient times. For example Aristotle in his History of Animals states "The pig is the only animal known to be subject to measles." ${ }^{14}$ By this he does not mean the childhood disease with which we are familiar today but the "measly" texture of tissue infected with cysticerci. There is also clear evidence that the disease occurred in North Africa where Caesar spent more than six months. The Ebers Papyrus mentions tapeworms being present in ancient Egypt and cysticercosis has been found in Egyptian mummies most recently in an autopsy of a young woman who lived around the first century BC. ${ }^{15}$ The proscription of the eating of pork by the Christian Old Testament, the Islamic Qur'an and the Jewish Torah may have contributed to the subsequent elimination of the disease from endemic areas where these religions were practiced.

As noted above, the best documented of Caesar's seizures was at Thapsus in 46BC about a year after he first traveled to Egypt. This would be consistent with the slow progression of the disease if he acquired it in North Africa. Plutarch states that he had another seizure in Cordoba in Spain where he led his troops shortly after Thapsus. However he was also in that city three years earlier as governor so which of these two visits Plutarch is referring to is unclear. It is likely the second visit as it would be unusual for someone with late onset untreated epilepsy from any cause to go three years before a second convulsion occurred. If it is the first visit, then Caesar would have to have been exposed to the disease during his extensive travels in southern Europe since he had not yet been to Africa.

Cysticercosis is an extremely contagious but treatable disease contracted from a person harboring the pig tapeworm Taenia solium (Figure 2) which develops after the consumption of undercooked pork containing the larval stage or cysticercus. ${ }^{16} \mathrm{~A}$ single 1 to 8 meter long worm attached to the wall of the small intestine liberates tens of thousands of eggs that are passed into the local environment where they remain viable for up to two

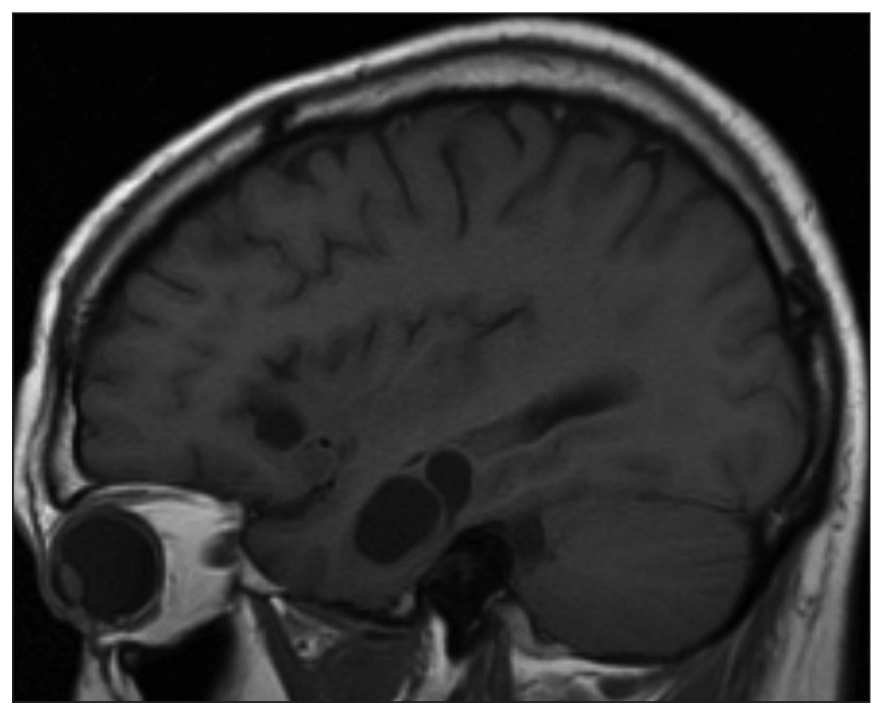

Figure 4: Sagittal MRI of the brain showing multiple cysts in a patient presenting with focal seizures.

months. Eggs ingested by pigs mature into the larval form of the disease that continue the cycle (Figure 3). Humans acquire cysticercosis by ingesting food contaminated with Taenia solium eggs or through autologous self contamination. Part of the egg called an oncosphere penetrates the gut wall and migrates to various tissues where it matures into the larval worm or scolex inside a fluid filled cyst, the cysticercus. Neurocysticercosis occurs when one or more of these cysts form in the brain (Figure 4). Focal epilepsy is the primary and often only clinical manifestation generally beginning many months after the initial infection. ${ }^{16}$ The condition is so common in some regions that even today, adults who present with focal seizures in an endemic area such as parts of India or South America are considered to have neurocysticercosis until proven otherwise.

A definitive diagnosis of the cause of Julius Caesar's epilepsy cannot be made but the clinical and epidemiological evidence suggests that had he the benefit of modern neuroimaging, one or more small cysts containing a larval worm of neurocysticercosis could well have been the finding. That epilepsy and its associated psychosocial burden may have contributed to the downfall of this great historical figure is an intriguing proposition.

One could question how Caesar was able to maintain his preeminence as a public figure while suffering from a condition that in ancient times was associated with a social stigma as an affliction imposed on people by the gods. He may have turned his epilepsy into a positive sign implying that his seizures indicated that he was in fact selected for special attention by the gods who also favored him to be dictator of all Rome. On the other hand, at least on one occasion he is known to have used his epilepsy as an excuse after offending a group of senators when he failed to stand to show them respect: "he imputed it to his disease saying that their wits are not perfect which have his disease the falling evil". ${ }^{2}$ Although some have suggested that he indeed had a partial seizure that day, Plutarch is clear that his 
actions were a deliberate attempt to demonstrate his superiority and not a result of any medical condition. For a man who sought absolute control and authority over Rome and its citizens to develop a disease characterized by the ultimate in loss of control, a convulsion, there must have been a major psychological impact including the possibility of development of comorbid depression. The sleep disturbance alluded to by Suetonius could have related to either depression or epilepsy and may have also influenced Caesar's ability to function at a high level. Was all of this enough to dampen the enthusiasm and ambition of this great man? Had his health not been affected, would Caesar have achieved his ultimate goal of becoming king of Rome? Had that happened, it would likely have altered the entire course of history of western civilization.

\section{ACKNOWLEDGEMENT}

The author thanks Drs. Jorge Burneo and Seetharam Raghavendra for discussions regarding neurocysticercosis and its impact in Peru and India.

\section{REFERENCES}

1. Wiebe S, Bellhouse DR, Fallahay C, Eliasziw M. Burden of epilepsy: the Ontario Health Survey. Can J Neurol Sci. 1999;26: 263-70.

2. Carr RH. Plutarch's life of Julius Caesar in North's translation. Oxford: Clarendon Press; 1908.

3. Suetonius GV. (English translation by Rolfe JC). Cambridge MA, London: Wm Heinemann Ltd / Harvard University Press; 1964.

4. Lennox WG. Epilepsy and related disorders. Vol 2. Boston: Little, Brown and Co; 1960. p. 707.

5. Cawthorne T. Julius Caesar and the falling sickness. Laryngoscope. 1958;68:1442-50.

6. Hughes JR. Dictator Perpetuus: Julius Caesar--did he have seizures? If so, what was the etiology? Epilepsy Behav. 2004;5:756-64.

7. Ehrenstein V, Pedersen L, Holsteen V, Larsen H, Rothman KJ, Sørensen HT. Postterm delivery and risk for epilepsy in childhood. Pediatrics. 2007;119:554-61.

8. Gomez JG, Kotler JA, Long JB. Was Julius Caesar's epilepsy due to a brain tumor? J Fla Med Assoc. 1995;82:199-201.

9. Lieu AS, Howng SL. Intracranial meningiomas and epilepsy: incidence, prognosis and influencing factors. Epilepsy Res. 2000;38:45-52.

10. Jackson HJ. Cases of epilepsy associated with syphilis. Med Times Gaz. 1861;1:648-58.

11. Sinha S, Harish T, Taly AB, Murthy P, Nagarathna S, Chandramuki A. Symptomatic seizures in neurosyphilis: an experience from a university hospital in south India. Seizure. 2008;17:711-6.

12. Kanner AM. Depression and epilepsy: a review of multiple facets of their close relation. Neurol Clin. 2009; 27:865-80.

13. Nash TE, Del Brutto OH, Butman JA, et al. Calcific neurocysticercosis and epileptogenesis. Neurology. 2004;62: 1934-8.

14. Aristotle. The history of animals: Book VIII. 350BC.

15. Bruschi F, Masetti M, Locci MT, et al. Short report: cysticercosis in an Egyptian mummy of the late ptolemaic period. Am J Trop Med Hyg. 2006;74:598-9.

16. Del Brutto OH, Sotello J, Roman GC. Neurocysticercosis: a clinical handbook. Lisse: Swets and Zeitlinger; 1998. 